\title{
Optimal Dynamic Routing Protocols for Agro-Sensor Communication in MANETs
}

\author{
Kazy Noor E Alam Siddiquee \\ Department of Computer Science and Engineering \\ University of Science and Technology Chittagong \\ Foy’s Lake, Chittagong, Bangladesh
}

Karl Andersson

Pervasive and Mobile Computing Laboratory

Luleå University of Technology

SE-931 87 Skellefteå, Sweden

\author{
Faria Farjana Khan \\ Department of Computer Science and Engineering \\ University of Science and Technology Chittagong \\ Foy's Lake, Chittagong, Bangladesh \\ Mohammad Shahadat Hossain \\ Department of Computer Science and Engineering \\ University of Chittagong \\ University-4331, Bangladesh
}

\begin{abstract}
Recent developments in the area of Wireless sensor networks and Mobile ad hoc networks provide flexible and easyto-deploy communication means for a wide range of applications without any need for an infrastructure being pre-configured. Our paper studies performance of proactive and reactive routing protocols in a scenario with agro-sensors. Our results, achieved by simulating a network both in OPNET Modeler and NS2, show that the AODV routing protocol performs better for a large-scale network (where node density is higher) while the DSR routing protocol performs better in a small-scale network given the particular scenario we studied.
\end{abstract}

Keywords-Wireless sensor networks; Mobile ad hoc networks; Proactive routing protocols; Reactive routing protocols; Agrosensing.

\section{INTRODUCTION}

Agriculture in developing countries depends on several natural and environmental activities, such as irrigation, seeding, harvesting, flood risk measurement and prediction. Activities need to be automated, synchronized with other activities for better production, satisfying the needs of the farmers. Food security is an important issue since systems aiming at ensuring optimal production of crops form a vital part of any country's overall security system.

Since agricultural fields are not always suitable for deploying regular infrastructure-based network models, mobile ad-hoc networks (MANETs) are considered as an alternative suitable approach for deploying wireless sensor networks (WSNs)

Wireless sensor network is applicable for Military purposes and specifically for military situation awareness, sensing intruders, detection of movements of rivals on land and sea area, and surveillance of battlefields. Although this paper describes performance of proactive and reactive routing protocols for agricultural sensors to be used for agricultural fields in Bangladesh, these protocols can be utilized to detect, collect, distribute, synthesize, and monitor environmental risks. Moreover, these protocols are too simple to act against network level attacks and some of the issues such as attacks against sensor nodes, secure management groups and secure aggregation of data should be taken into consideration for security concerns.

As the Ad hoc On-Demand Distance Vector (AODV) Routing protocol [1] performs better for large-scale networks (where node density is higher) while the Dynamic Source Routing (DSR) protocol [2] performs better in a small-scale network, an aggregated customized version of AODV and DSR is proposed for optimal future performance. This paper studies performance of proactive and reactive routing protocols in such a scenario.

The remainder of the paper is structured in the following way: Section 2 surveys related work, while Section 3 details our scenario and simulation settings. Section 4 presents and discusses our results, while Section 5 concludes our study and indicates future work.

\section{RELATED WORK}

Panchard [3] highlighted activities for small landowners and farmers while they were being suffered with water scarcity and some of the environmental challenges were pointed out using WSN. A WSN for agricultural field, highlighting applications with some topological arrangements such as, point-to-point master-slave, short hop or multi hop arrangements with IPv6 mentioned in [4]. Smart risk assessment systems to predict flood water level by using Belief Rule Base (BRB) have been identified in [5]. In addition, an architecture for building a decision support system for flood prediction using a heterogeneous WSN was proposed in [6]. An agricultural application developed by using WSN where various environmental parameters considered [7]. Another multilevel sensor network was designed in [8] for acquisition and processing of environmental data to support farming and agricultural activities. In [9], Intanagonwiwat et al. proposed a diffusion mechanism for taking advantage of different aspects of WSN not being available in general purpose networks.

Since long ago, studies on WSNs and MANETs have performed under certain protocols suits. MANET does not need central access points and they have to face several challenges especially in topological changes (dynamically), lower transmission of power and links (asymmetric) in network 
[10] whereas simulation software like OPNET, OMNET++, COOJA, and NS2 were used to study performance of proactive and reactive routing protocols. Performance of DSR and DSDV routing protocols have been compared (under NS2) in terms of end-to-end delay, packet delivery, and throughput [11].

In 2007, performances of AODV, DSR and OLSR were studied [12] and proactive routing protocol was found to be superior to reactive ones under CBR traffic of MANETs. Other studies considered minimum power routing, self-organizing protocols, minimum transmission of energy and performances on protocol stack (IP based) in WSN [13][14].

Performance of LEACH protocols was evaluated in [15] for selection of routing cluster-heads to collect local information and transmit in WSN. A mathematical framework was evaluated and proposed in [16] analyzing performances (using discrete-event Qualnet simulations) of proactive and reactive routing protocols in MANETs. The result showed a parametric view of performances of protocols and a routing logic was synthesized with performances of MAC protocols. A comparative analysis of LEACH, TCAC and DSBCA was performed and clustering protocols were proposed for load balancing measurement [17]. How consensus algorithms face Challenges in WSN was highlighted in [18]. Hayes et al. [19] proposed a location aware sensor routing (LASeR) protocol. A prediction technique (location challenges) using the Kringing Interpolation technique was proposed with a prediction algorithm in [20]. A model of heterogeneous WSN (consisting both BPSN and EHSN with a cost function oriented routing strategy) was proposed with some better-attained parameters such as end-to-end path reliability, cost and energy consumption for a better QoS [21].

\section{SCENARIO AND SIMULATION ENVIRONMENT}

Our scenario is centered on a village in the district of Chittagong, Bangladesh, where sensors are placed in plane land for obtaining measurements of soil moisture and PH values. A low density of sensor nodes is assumed, and both sources and destinations have routing protocols deployed.

Three distinct parameters (End-to-end delay, network load and throughput) are studied and analyzed in both OPNET and NS2. Table 1 and 2 summarize the settings for each simulation environment.

TABLE I. SIMULATION PARAMETERS (OPNET)

\begin{tabular}{|l|l|}
\hline \multicolumn{1}{|c|}{ Parameter } & \multicolumn{1}{c|}{ Value } \\
\hline Simulator & OPNET Modeler 17.5 \\
\hline Area & $1000 * 1000 \mathrm{~m}$ \\
\hline Network size & 10 nodes, 20 nodes \\
\hline Protocols & DSR, AODV, and GRP \\
\hline Simulation time & $900 \mathrm{~s}$ \\
\hline Address mode & IPv4 \\
\hline
\end{tabular}

TABLE II. SIMULATION PARAMETERS (NS2)

\begin{tabular}{|l|l|}
\hline \multicolumn{1}{|c|}{ Parameter } & \multicolumn{1}{c|}{ Value } \\
\hline Radio model & TwoRay Ground \\
\hline Protocols & DSDV, AODV, DSR \\
\hline Traffic source & Constant Bit Rate \\
\hline Packet size & 512 bytes \\
\hline Max speed & $10 \mathrm{~m} / \mathrm{s}$ \\
\hline Area & $500 * 500 \mathrm{~m}$ \\
\hline Number of nodes & $50 \mathrm{nodes}, 100$ nodes \\
\hline Application & FTP \\
\hline MAC & Mac/802_11 \\
\hline Simulation time & $\begin{array}{l}20 \mathrm{~s}, 40 \mathrm{~s}, 60 \mathrm{~s}, 80 \mathrm{~s}, \text { and } \\
100 \mathrm{~s}\end{array}$ \\
\hline
\end{tabular}

\section{RESUlTS AND DISCUSSION}

This section summarizes the results obtained from each simulation.

\section{A. Performance of AODV, DSR, and GRP (using OPNET) \\ 1) End-to-end delay and packets dropped}

TABLE III. TOTAL PACKETS DROPPED

\begin{tabular}{|l|l|l|}
\hline \multicolumn{1}{|c|}{ Protocol } & \multicolumn{1}{c|}{ 10 nodes } & \multicolumn{1}{c|}{ 20 nodes } \\
\hline AODV & 2 & 3 \\
\hline DSR & constant & constant \\
\hline GRP & 150 & 199 \\
\hline
\end{tabular}

There is a little difference between AODV and DSR. Data dropped in DSR is in $5 \mathrm{sec}$ and in AODV, it is in $6 \mathrm{sec}$. and dropping of packets is higher in GRP (in $120 \mathrm{sec}$ ) compared to AODV and DSR in Table 3.

It is quite frequent that for 10 nodes, GRP is higher than AODV and DSR. Performance of DSR for 10 and 20 nodes are quite similar and optimal than that of AODV and GRP. GRP shows the highest curve in terms of packets dropped in this MANET. End-to-end delay is measured and shown in Table 4. Result of simulation depict that end-to-end delay in GRP is lowest among these three protocols in 10 nodes whereas for 20 nodes, it is higher.

TABLE IV. OVERALL END-TO-END DELAY

\begin{tabular}{|l|l|l|}
\hline \multicolumn{1}{|c|}{ Protocol } & \multicolumn{1}{|c|}{ 10 nodes } & \multicolumn{1}{c|}{ 20 nodes } \\
\hline AODV & 0.00019 & 0.00044 \\
\hline DSR & 0.00035 & 0.00059 \\
\hline GRP & 0.00015 & 0.00043 \\
\hline
\end{tabular}

The difference between AODV and GRP is very small when end to end delay in GRP is $0.00015 \mathrm{sec}$ and in AODV is equal to $0.00019 \mathrm{sec}$. Table 4 shows that delay in DSR is 
higher than that of AODV and GRP. DSR has initial Delay compared to others. Node performance shows that end-to-end delay is highest for DSR for both 10 and 20 nodes.

\section{2) Network load}

Another parameter, the network load, is measured and the result is shown below in Table 5:

TABLE V. OVERALL NETWORK LOAD

\begin{tabular}{|l|l|l|}
\hline \multicolumn{1}{|c|}{ Protocol } & \multicolumn{1}{|c|}{ 10 nodes } & \multicolumn{1}{c|}{ 20 nodes } \\
\hline AODV & 3890.926 & 1209.348 \\
\hline DSR & 1580.448 & 8040.236 \\
\hline GRP & 1345.192 & 5184.101 \\
\hline
\end{tabular}

Several results have been generated for AODV, DSR and GRP protocols. When number of nodes is 10 , performance of AODV is the better than the other two. For AODV, the average peak value for network load is $3890.926 \mathrm{~b} / \mathrm{s}$. For DSR, it is $1580.448 \mathrm{~b} / \mathrm{s}$ and for GRP, it is $1345.192 \mathrm{bits} / \mathrm{sec}$. For the other scenario, for 20 nodes (mobile), again AODV performs better than other two routing protocols. Table 6 shows that the network load in AODV network for both 10 and 20 nodes increases till the end of the simulation performance. AODV has maximum Network Load. Ordering of protocols according to network load can be specified as AODV $>$ DSR $>$ GRP according to the obtained result.

\section{3) Throughput}

The last parameter, throughput, is measured in perspective of transmission and receiving of data and the result is shown in Table 7 below. The first scenario shows here that AODV attains optimal throughput than other two protocols for both 10 and 20 nodes. DSR has the lowest throughput than that of others in 10 nodes where GRP has the lowest in 20 nodes environment.

TABLE VI. NETWORK LOAD RESULTS

\begin{tabular}{|l|l|l|}
\hline \multicolumn{1}{|c|}{ Protocol } & \multicolumn{1}{|c|}{ 10 nodes } & \multicolumn{1}{c|}{ 20 nodes } \\
\hline AODV & 25678 & 140198 \\
\hline DSR & 15960 & 95988 \\
\hline GRP & 20189 & 45124 \\
\hline
\end{tabular}

Throughput rate of AODV reaches to the peak (25678 bits/sec) in time where DSR provides throughput rate more than $15960 \mathrm{~b} / \mathrm{s}$ while it decreases at the middle. GRP provides a rate of $20189 \mathrm{~b} / \mathrm{s}$ (Table 6).

The results shown below in Table 7, GRP is not the optimal choice for a MANET considering three parameters (end to end delay, network load and throughput). AODV performs better than the other two and GRP performs worst. Therefore, reactive routing protocols dominate proactive ones considering these three parameters. Different number of nodes has a greater impact on consuming energies and performing in wireless ad-hoc networks (sensor networks).
TABLE VII. TOTAL EXPERIMENT RESULTS

\begin{tabular}{|c|c|c|c|c|}
\hline Nodes & Metric & AODV & DSR & GRP \\
\hline \multirow{3}{*}{10} & Delay & 0.00011 & 0.00025 & 0.00019 \\
\cline { 2 - 5 } & Network Load & 3890.926 & 1580.448 & 1345.194 \\
\cline { 2 - 5 } & Throughput & 25678 & 15500 & 20916 \\
\hline \multirow{3}{*}{20} & Delay & 0.00044 & 0.00052 & 0.00043 \\
\cline { 2 - 5 } & Network Load & 1209.348 & 8040.236 & 5184.101 \\
\cline { 2 - 5 } & Throughput & 140198 & 95988 & 45124 \\
\hline
\end{tabular}

\section{B. Performance of AODV, DSR, and DSDV (using NS2)}

\section{1) Throughput}

As shown in Table 8 below, DSR performs best though AODV stays in a steadier and stable state in different time in NS2. Both DSDV and DSR have more fluctuations than AODV in different time.

TABLE VIII. AVERAGE THROUGHPUT RESULTS

\begin{tabular}{|c|c|c|c|c|c|c|}
\cline { 2 - 7 } \multicolumn{1}{c|}{} & \multicolumn{3}{c|}{ 50 nodes } & \multicolumn{3}{c|}{ 100 nodes } \\
\hline $\begin{array}{c}\text { Pause } \\
\text { time } \\
\text { (sec) }\end{array}$ & DSDV & AODV & DSR & DSDV & AODV & DSR \\
\hline 20 & 314933 & 599851 & 680597 & 1738.67 & 691435 & 680597 \\
\hline 40 & 326862 & 547095 & 579319 & 90390.9 & 587314 & 579794 \\
\hline 60 & 230359 & 474272 & 492096 & 57521.5 & 499404 & 493155 \\
\hline 80 & 260288 & 439949 & 451614 & 127322 & 458831 & 452834 \\
\hline 100 & 276990 & 419988 & 428177 & 166929 & 435074 & 429315 \\
\hline
\end{tabular}

2) Network load

From the results shown below in Table 9 it is quite clear that DSR performs better than the other two. DSDV has more fluctuations than those of AODV and DSR. AODV remains in a stable state.

TABLE IX. NETWORK LOAD RESULTS

\begin{tabular}{|c|c|c|c|c|c|c|}
\cline { 2 - 7 } \multicolumn{1}{c|}{} & \multicolumn{3}{c|}{ 50 nodes } & \multicolumn{3}{c|}{ 100 nodes } \\
\hline $\begin{array}{c}\text { Pause } \\
\text { time } \\
\text { (sec) }\end{array}$ & DSDV & AODV & DSR & DSDV & AODV & DSR \\
\hline 20 & 97.6169 & 99.0667 & 99.1919 & 80 & 99.1886 & 99.1896 \\
\hline 40 & 98.8569 & 99.1201 & 99.2434 & 96.6102 & 99.1795 & 99.2031 \\
\hline 60 & 98.4053 & 99.3528 & 99.4335 & 96.4844 & 99.3854 & 99.404 \\
\hline 80 & 98.8518 & 99.488 & 99.5467 & 97.2525 & 99.5086 & 99.5233 \\
\hline 100 & 98.4413 & 99.5764 & 99.6223 & 97.4224 & 99.5907 & 99.6028 \\
\hline
\end{tabular}

3) End-to-end delay

Though AODV has higher delay than on an average (see table 10), but still it remains stable. DSDV fluctuates more in both 50 and 100 nodes. For 50 nodes DSDV performs better whereas for 100 nodes DSR is superior to the other two. 
TABLE $X . \quad$ END-TO-END DELAY

\begin{tabular}{|c|c|c|c|c|c|c|}
\cline { 2 - 7 } \multicolumn{1}{c|}{} & \multicolumn{3}{c|}{ 50 nodes } & \multicolumn{3}{c|}{ 100 nodes } \\
\hline $\begin{array}{c}\text { Pause } \\
\text { time } \\
\text { (sec) }\end{array}$ & DSDV & AODV & DSR & DSDV & AODV & DSR \\
\hline 20 & 0.1209 & 0.19027 & 0.09408 & 0.32939 & 0.17863 & 0.08187 \\
\hline 40 & 0.08995 & 0.17764 & 0.11929 & 0.12486 & 0.17468 & 0.1074 \\
\hline 60 & 0.09035 & 0.19782 & 0.16596 & 0.16703 & 0.1938 & 0.13623 \\
\hline 80 & 0.13211 & 0.20944 & 0.18486 & 0.24473 & 0.20469 & 0.13837 \\
\hline 100 & 0.13818 & 0.21646 & 0.20101 & 0.23451 & 0.21308 & 0.14485 \\
\hline
\end{tabular}

\section{CONCLUSION AND FUTURE WORK}

Both OPNET and NS2 results depict better performance for two protocol suits (RRP and PRP). Though several researches have been performed in this same issue, but we have drawn a strong scenario with two simulation environments to highlight characteristics of performances of those protocols under three parameters. Sensors in a WSN will be driven with a specific requirement of higher or lower density networks.

Ad hoc networks better suits in both topological and management issues in agricultural fields in Bangladesh and hence, this research is carried out forming MANETs with WSN to assess performances of protocols.

Limitation of this research shows lack of analysis on higher density sensor networks where thousands of sensors may be used in a single MANET of WSN. But, according to requirements of agricultural fields and environmental effects, lower density network of WSN is suitable and it performs better.

Moreover, using a single topology in MANET, all cases are simulated here as in agricultural lands of Bangladesh as limited scopes are there to apply general topologies. Therefore, other topologies were not the concern in research objectives.

As energy consumption is not the primary objective of this study, protocols are not assessed in terms of their energy consumption rate. Only end-to-end delay, network load and throughputs are concerning objectives of this research.

Comparison of three major routing protocols in a MANET of sensor network shows that in terms of end-to-end delay, network load and throughput AODV performs better than other three. In other sense, reactive routing protocols perform better than proactive routing protocols.

AODV routing protocol better performs for a large-scale network (where node density is higher) and DSR routing protocol performs better in a small-scale network. Performances of DSDV in accordance to these three parameters do not stay stable; rather fluctuates. Therefore, it cannot be preferable for any ad-hoc network where topology and maintenance are other concerning issues. GRP performs worst of all three (AODV, DSR, and GRP) in OPNET simulation.

\section{ACKNOWLEDGMENT}

This work has been supported by the Swedish Research Council under grant 2014-4251.

\section{REFERENCES}

[1] C. Perkins, E. Belding-Royer, and S. Das, "Ad hoc On-Demand Distance Vector (AODV) Routing," RFC 3561, IETF, 2003.

[2] D. Johnson, Y. Hu, and D. Maltz, "The Dynamic Source Routing Protocol for Mobile Ad Hoc Networks for IPv4," RFC 4728, IETF, 2007.

[3] J. Panchard, "Wireless sensor networks for marginal farming in India," PhD. thesis, École Polytechnique Fédérale de Lausanne (EPFL), Switzerland, 2008. Available: http://dx.doi.org/10.5075/epfl-thesis-4172.

[4] S. Shiravale and S. M. Bhagat, "Wireless Sensor Networks in Agriculture Sector Implementation- Implementation and Security Measures," International Journal of Computer Applications, 92(13):2529, 2014.

[5] K. Andersson and M. S. Hossain, "Smart Risk Assessment Systems using Belief-rule-based DSS and WSN Technologies," Proceedings of the 2014 4th International Conference on Wireless Communications, Vehicular Technology, Information Theory and Aerospace \& Electronic Systems (VITAE), 2014.

[6] K. Andersson and M. S. Hossain, "Heterogeneous wireless sensor networks for flood prediction decision support systems," Proceedings of the 2015 IEEE Conference on Computer Communications Workshops (INFOCOM WKSHPS), 2015.

[7] T. D. Le and D. H. Tan, "Design and deploy a wireless sensor network for precision agriculture," Proceedings of the 2015 2nd National Foundation for Science and Technology Development Conference on Information and Computer Science, 2015.

[8] V. Romanov, I. Galelyuka, and Ye. Sarakhan, "Wireless sensor networks in agriculture," Proceedings of 2015 IEEE Seventh International Conference on Intelligent Computing and Information Systems (ICICIS), 2015.

[9] C. Intanagonwiwat, R. Govindan, and D. Estrin, "Directed diffusion: a scalable and robust communication paradigm for sensor networks," Proceedings of the 6th annual international conference on Mobile Computing and Networking, 2000.

[10] C. Perkins and P. Bhagwat, "Highly dynamic destination-sequenced distance-vector routing (DSDV) for mobile computers," Proceedings of the conference on Communications architectures, protocols, and applications (SIGCOMM), 1994.

[11] Mandhare Vaishali V. and R. C. Thool, "Comparing the performance of proactive and reactive routing protocol in Mobile Ad-Hoc Network," Proceedings of the 2015 International Conference on Industrial Instrumentation and Control, 2015.

[12] S. Vanthana and V. Sinthu Janita Prakash, "Comparative Study of Proactive and Reactive AdHoc Routing Protocols Using NS2," Proceedings of the 2014 World Congress on Computing and Communication Technologies, 2014.

[13] S. Thombre, R. Ul Islam, K. Andersson, and M. S. Hossain, "Performance Analysis of an IP based Protocol Stack for WSNs," Proceedings of the 2016 IEEE Conference on Computer Communications Workshops (INFOCOM WKSHPS), 2016.

[14] S. Thombre, R. Ul Islam, K. Andersson, and M. S. Hossain, "IP based Wireless Sensor Networks: Performance Analysis using Simulations and Experiments," Journal of Wireless Mobile Networks, Ubiquitous Computing, and Dependable Applications (JoWUA) 7(3):53-76, 2016.

[15] W. R. Heinzelman, J. Kulik, and H. Balakrishnan, "Adaptive protocols for information dissemination in wireless sensor networks," Proceedings of the Fifth Annual ACM/IEEE International Conference on Mobile Computing and Networking, 1999.

[16] H. Xu, X. Wu, H. R. Sadjadpour, and J. Garcia-Luna-Aceves, "A Unified Analysis of Routing Protocols in MANETs," IEEE Transactions on Communications 58(3):911-922, 2010. 
[17] S. Siavoshi, Y. S. Kavian, and H. Sharif, "Load-balanced energy efficient clustering protocol for wireless sensor networks," IET Wireless Sensor Systems 6(3):67-73, 2016.

[18] A. Khosravi and Y. S. Kavian, "Challenging issues of average consensus algorithms in wireless sensor networks," IET Wireless Sensor Systems 6(3):60-66, 2016.

[19] T. Hayes and F. H. Ali, "Location aware sensor routing protocol for mobile wireless sensor networks," IET Wireless Sensor Systems 6(2):49-57, 2016
[20] A. Ali, A. Ikpehai, B. Adebisi, and L. Mihaylova, "Location prediction optimisation in WSNs using Kriging interpolation," IET Wireless Sensor Systems 6(3):74-81, 2016.

[21] A. E. Zonouz, L. Xing, V. M. Vokkarane, and Y. L. Sun, "Hybrid wireless sensor networks: a reliability, cost and energy-aware approach," IET Wireless Sensor Systems 6(2):42-48, 2016. 